\title{
DA-1229, a dipeptidyl peptidase IV inhibitor, protects against renal injury by preventing podocyte damage in an animal model of progressive renal injury
}

\author{
Jee Eun Lee ${ }^{1,5}$, Jung Eun Kim²,5, Mi Hwa Lee², Hye Kyoung Song ${ }^{2}$, Jung Yeon Ghee ${ }^{2}$, Young Sun Kang ${ }^{2}$, \\ Hye Sook Min², Hyun Wook Kim', Jin Joo Cha², Jee Young Han ${ }^{3}$, Sang Youb Han ${ }^{4}$ and Dae Ryong Cha ${ }^{2}$
}

\begin{abstract}
Although dipeptidyl peptidase IV (DPPIV) inhibitors are known to have renoprotective effects, the mechanism underlying these effects has remained elusive. Here we investigated the effects of DA-1229, a novel DPPIV inhibitor, in two animal models of renal injury including $d b / d b$ mice and the adriamycin nephropathy rodent model of chronic renal disease characterized by podocyte injury. For both models, DA-1229 was administered at $300 \mathrm{mg} / \mathrm{kg} / \mathrm{day}$. DPPIV activity in the kidney was significantly higher in diabetic mice compared with their nondiabetic controls. Although DA-1229 did not affect glycemic control or insulin resistance, DA-1229 did improve lipid profiles, albuminuria and renal fibrosis. Moreover, DA-1229 treatment resulted in decreased urinary excretion of nephrin, decreased circulating and kidney DPPIV activity, and decreased macrophage infiltration in the kidney. In adriamycin-treated mice, DPPIV activity in the kidney and urinary nephrin loss were both increased, whereas glucagon-like peptide-1 concentrations were unchanged. Moreover, DA-1229 treatment significantly improved proteinuria, renal fibrosis and inflammation associated with decreased urinary nephrin loss, and kidney DPP4 activity. In cultured podocytes, DA-1229 restored the high glucose/angiotensin II-induced increase of DPPIV activity and preserved the nephrin levels in podocytes. These findings suggest that activation of DPPIV in the kidney has a role in the progression of renal disease, and that DA-1229 may exert its renoprotective effects by preventing podocyte injury.
\end{abstract}

Laboratory Investigation (2016) 96, 547-560; doi:10.1038/labinvest.2016.34; published online 15 February 2016

Dipeptidyl peptidase IV (DPPIV) inhibition is believed to exert its antidiabetic effects by enhancing the production of incretins such as glucose-dependent insulinotropic polypeptide and glucagon-like peptide-1 (GLP-1), and GLP-1 receptors have also been found in extra-pancreatic tissues and incretin-based agents have been shown to have possible pleiotropic actions beyond glucose control. ${ }^{1-6}$ Many experimental and clinical trials have concluded that DPPIV inhibition decreases albuminuria in DN and can potentially delay the onset and progression of $\mathrm{DN}$, in addition to improving kidney function in glycemic controls. ${ }^{7-14}$

Numerous studies have provided evidence that podocyte dysfunction, such as podocyte loss, has a central role in the development and progression of DN. ${ }^{15,16}$ For example, the decreased nephrin expression observed in $\mathrm{DN}$ has been associated with increased albuminuria, and recent reports have also demonstrated that DPPIV expression is upregulated in the glomeruli of patients with DN. ${ }^{7,17-19}$ Moreover, DPPIV inhibition has been shown to delay DN progression by attenuating podocyte injury via a glucose-independent mechanism. ${ }^{7}$ Furthermore, DPPIV inhibition has been shown to improve proteinuria, podocyte function in an animal model of obesity-related glomerulopathy. ${ }^{20}$ Taken together, these findings indicate that DPPIV inhibition may affect podocyte function in $\mathrm{DN}$.

However, few reports have evaluated the role of DPPIV on renal injury, specifically on podocyte injury, in a mouse model of type 2 diabetes. Thus, here we investigated the effects of DA-1229, a novel DPPIV inhibitor, on DN in $d b / d b$ mice. In addition, we also utilized a mouse model of chronic

\footnotetext{
${ }^{1}$ Division of Nephrology, Department of Internal Medicine, Wonkwang University, Gunpo, Korea; ${ }^{2}$ Division of Nephrology, Department of Internal Medicine, Korea University Ansan Hospital, Ansan, Korea; ${ }^{3}$ Department of Pathology, Inha University, Incheon, Korea and ${ }^{4}$ Division of Nephrology, Department of Internal Medicine, Inje University, Ilsan, Korea

Correspondence: Professor DR Cha, MD, Division of Nephrology, Department of Internal Medicine, Korea University Ansan Hospital, 516 Kojan-Dong, Ansan City,

Kyungki-Do, Ansan 425-020, Korea.

E-mail: cdragn@unitel.co.kr

${ }^{5}$ These authors contributed equally to this work.
}

Received 31 July 2015; revised 17 December 2015; accepted 17 January 2016 
progressive kidney disease characterized by podocyte injury, adriamycin nephropathy, to examine the effect of DPPIV inhibition on the progression of renal disease. In addition, to elucidate the molecular mechanism by which DPPIV acts, we performed in vitro experiments using cultured podocytes to evaluate the effects of high glucose and angiotensin II on DPPIV activity and nephrin levels.

\section{MATERIALS AND METHODS Animal Studies}

Animal studies were conducted in two different mouse models of disease, type 2 diabetes and adriamycin nephropathy. For the type 2 diabetes model, six-week-old male diabetic $d b / d b$ mice (C57BLKS/J-lepr $\mathrm{db}^{\mathrm{db}} /$ lepr $^{\mathrm{db}}$ ) and male nondiabetic $d b / m$ mice (C57BLKS/J-lepr $r^{d b} /+$ ) were purchased from The Jackson Laboratory (Sacramento, CA, USA). DA-1229 (evogliptin) tartrate, a DPPIV inhibitor, was obtained from Dong-A ST Research Institute (Yongin, Republic of Korea). Mice were divided into three experimental groups ( $n=8$ per group): nondiabetic $d b / m$ mice as nondiabetic controls, untreated $d b / d b$ mice and drug-treated $d b / d b$ mice. Mice were fed with either normal chow or $0.3 \%$ DA-1229-chow admixture (mean administered dose of $297.2 \pm 0.10 \mathrm{mg} / \mathrm{kg} /$ day) for 12 weeks from 8 weeks of age. For the adriamycin model, 10-week-old male BALB/c mice were administered a single intravenous injection of adriamycin (doxorubicin hydrochloride; Sigma, St Louis, MO, USA) at $13 \mathrm{mg} / \mathrm{kg}$. These conditions were chosen based on preliminary experiments showing that a single tail vein injection of this dose induced significant proteinuria and progressive glomerulosclerosis by 3 weeks after injection. For the adriamycin model, preventive and therapeutic protocols were performed ( $n=7$ per group). To analyze the preventive effects of DA-1229 in adriamycin model, DA-1229 was administered in mixed chow at a dose of $300 \mathrm{mg} / \mathrm{kg} /$ day for 3 weeks beginning with the adriamycin injection. Mice were then killed 3 weeks after the adriamycin injection. For the therapeutic protocol, DA-1229 treatment was initiated 3 weeks after adriamycin injection and the treatment was continued for 2 weeks. Mice were then killed at 5 weeks post-adriamycin injection. All mice were provided with a standard diet and water and were maintained in a temperature-controlled $\left(23 \pm 2^{\circ} \mathrm{C}\right)$ and humidity-controlled $(55 \pm 5 \%)$ room with a 12-h light/12- h dark cycle. Daily food intake was monitored at regular intervals to confirm drug administration. During experiments, food intake, water intake, urine volume, body weight, fasting blood glucose concentration and $\mathrm{HbA1c}$ levels were measured monthly. Blood glucose levels were measured using the glucose oxidase-based method and plasma creatinine levels were determined by HPLC. Plasma insulin and adiponectin levels were measured using an ELISA kit (Linco Research, St Charles, MO, USA). The homeostasis model assessment index (HOMA-IR) was calculated by the following equation: fasting glucose $(\mathrm{mmol} / \mathrm{l}) \mathrm{x}$ fasting insulin $(\mathrm{mU} / \mathrm{l}) /$ 22.5. Plasma triglyceride and cholesterol analyses were performed using a GPO-Trinder kit (Sigma-Aldrich, St Louis, MO, USA). Plasma lipoprotein profiles were measured using a fast protein HPLC system. To determine urinary albumin excretion, individual mice were caged once each month in a metabolic cage, and urine was collected for $24 \mathrm{~h}$. Urinary albumin concentrations were determined by a competitive ELISA kit (ALPCO, Westlake, OH, USA). Urinary nephrin concentrations were also determined by an ELISA kit (Exocell, Philadelphia, PA, USA) and corrected according to urine creatinine concentrations. Plasma active GLP-1 levels were determined by an ELISA kit (Millipore, St Charles, MO, USA). Plasma MCP-1 concentrations were assessed by an ELISA kit (Abcam Plc, Cambridge, MA, USA). Plasma and urinary levels of 8-isoprostane were measured using an ELISA kit (Cayman Chemical, Ann Arbor, MI, USA). At the end of the study period, systolic blood pressure was measured using tail-cuff plethysmography with an LE 5001-Pressure Meter (Letica SA, Barcelona, Spain). Mice were killed under anesthesia through i.p. injections of sodium pentobarbital $(50 \mathrm{mg} / \mathrm{kg})$. All ELISA analyses were performed in triplicate, and the results were averaged. All experiments were conducted in accordance with NIH guidelines and with the approval of the Korea University Institutional Animal Care and Use Committee.

\section{DPPIV Activity Assay}

DPPIV activity was measured in plasma, cells and tissues as previously described. ${ }^{21}$ Briefly, $0-40 \mu \mathrm{M}$ of AMC (7-amino-4methylcoumarin) standard was loaded into each well and read fluorometrically at $\mathrm{Em} / \mathrm{Ex}=360 / 465 \mathrm{~nm}$, generating a linear standard curve. Next, $50 \mu \mathrm{l}$ of plasma sample was added to each of the 96-wells, followed by the addition of $50 \mu \mathrm{l}$ substrate solution (final concentrations 0.1 M HEPES, $50 \mu \mathrm{M}$ Gly-Pro-AMC and $50 \mu \mathrm{g} / \mathrm{ml} \mathrm{BSA)} \mathrm{per} \mathrm{well.} \mathrm{Free} \mathrm{AMC,} \mathrm{which}$ was released by DPPIV activity, was quantitated by fluorometric measurements every $25 \mathrm{~s}$ for $300 \mathrm{~s}$ using a Spectramax GEMINI XPS microplate reader (Molecular Devices, Sunnyvale, $\mathrm{CA}$, USA; $\mathrm{Em} / \mathrm{Ex}=360 / 465 \mathrm{~nm}$, target temperature $=25^{\circ} \mathrm{C}$ ). To analyze DPPIV activity in renal tissue and cells, frozen tissue $(10 \mathrm{mg})$ or cells $\left(2 \times 10^{6}\right)$ were homogenized in cold assay buffer $(25 \mathrm{mM}$ Tris- $\mathrm{HCl}, 140 \mathrm{mM} \mathrm{NaCl}, 10 \mathrm{mM} \mathrm{KCl}$, $\mathrm{pH} 7.5,0.1 \% \mathrm{BSA}$ ) and spun by centrifugation at $20000 \mathrm{~g}$ for $20 \mathrm{~min}$ at $4^{\circ} \mathrm{C}$. DPPIV activity in the lysates was measured as described above. DPPIV activity in each tissue sample was expressed as the amount of cleaved AMC per minute per gram of tissue $(\mu \mathrm{M} / \mathrm{min} / \mathrm{g}$ tissue $)$.

\section{Histological and Immunohistochemical Analysis}

Kidney and hepatic tissue samples were fixed in $4 \%$ paraformaldehyde and embedded in paraffin. Samples were cut into $4-\mu \mathrm{m}$ thick slices and stained with periodic acid-Schiff or hematoxylin and eosin. For immunohistochemical staining, sections were microwaved for 10-20 min to retrieve antigens for TGF- $\beta 1$, nephrin, $\alpha$-SMA, WT- 1 and F4/80 staining. Alternatively, sections were transferred to Biogenex 
Retrievit buffer (pH 8.0) (InnoGenex, San Ramon, CA, USA) and microwaved for 10-20 min for antigen retrieval for plasminogen activator inhibitor (PAI)-1 staining, or treated with trypsin (Sigma) for $30 \mathrm{~min}$ at $37^{\circ} \mathrm{C}$ to detect type IV collagen. To block endogenous peroxidase activity, $3.0 \%$ $\mathrm{H}_{2} \mathrm{O}_{2}$ in methanol was applied to the tissue sections for $20 \mathrm{~min}$. Samples were then incubated at room temperature for $60 \mathrm{~min}$ in 3\% BSA $/ 3 \%$ normal goat serum (type IV collagen, $\alpha$-SMA, WT- 1 and F4/80), 30 min with 5\% normal goat serum (nephrin), 15 min with $10 \%$ powerblock (PAI-1) or 30 min with $20 \%$ normal sheep serum (TGF- $\beta 1$ ). Slides were incubated overnight at $4{ }^{\circ} \mathrm{C}$ with rabbit polyclonal anti-TGF- $\beta 1$ antibodies (1:200; Santa Cruz Biotechnology), rabbit polyclonal anti-WT-1 antibodies (1:400, Santa Cruz Biotechnology), mouse monoclonal anti-F4/80 antibodies (1:100; Serotec, Raleigh, NC, USA), rabbit polyclonal anti-type IV collagen antibodies (1:150; BioDesign International, Sarco, ME, USA), guinea pig polyclonal anti-nephrin antibodies (1:50; PROGEN Biotechnik GmbH, Heidelberg, Germany), rabbit polyclonal anti-PAI-1 antibodies (1:60; American Diagnostica, Stamford, CT, USA) or rabbit polyclonal anti- $\alpha$-SMA antibodies (1:100; Santa Cruz Biotechnology). After overnight incubation, slides were incubated with secondary antibodies for $30 \mathrm{~min}$. Immunoreactive areas were detected by incubation at room temperature with a mixture of $0.05 \%$ 3,3-diaminobenzidine containing $0.01 \% \mathrm{H}_{2} \mathrm{O}_{2}$ followed by counterstaining with Mayer's hematoxylin. Negative control sections were stained under identical conditions but with a buffer solution instead of the primary antibody. Glomerular mesangial expansion in diabetic mice was scored semiquantitatively as described previously, ${ }^{22}$ and the degree of glomerulosclerosis in the adriamycin nephropathy model was scored according to the method described by Ma et al. ${ }^{23}$ Macrophages infiltrating the interstitium were counted and expressed as the number of macrophages per high-power field. After $\alpha$-SMA staining, the degree of tubulointerstitial fibrosis was assessed by a point-counting method as described previously. ${ }^{24}$ To evaluate the immunohistochemical staining for type IV collagen, TGF- $\beta 1$, PAI-1, WT-1 and F4/80, glomerular fields were graded semiquantitatively under a high-power field containing 50-60 glomeruli and an average score was calculated as described previously. ${ }^{22}$ All histologic examinations were conducted by a trained pathologist in a blinded manner.

\section{Analysis of Gene Expression by Real-Time Quantitative PCR}

Total RNA was extracted from renal cortical tissue samples and cells with Trizol reagent and further purified using an RNeasy Mini kit (Qiagen, Valencia, CA, USA). Primers were designed from respective gene sequences using Primer 3 software and the secondary structures of the templates were examined and excluded using $m$ fold software. The nucleotide sequences of all primers used in this study are shown in Table 1. Real-time quantitative PCR was performed using a
Table 1 Primer sequences for real-time quantitative PCR

\begin{tabular}{|c|c|}
\hline Target gene & Primer sequence (5' to $\left.3^{\prime}\right)$ \\
\hline GLP-1R, forward & GCCCATTCTCTTTGCTATCG \\
\hline GLP-1R, reverse & GCCTTCAGTTTGGAGACCAC \\
\hline PAl-1, forward & TCCTCATCCTGCCTAAGTTCTC \\
\hline PAl-1, reverse & GTGCCGCTCTCGTITACCTC \\
\hline TGF- $\beta 1$, forward & AGCCCGAAGCGGACTACTAT \\
\hline TGF- $\beta 1$, reverse & CTGTGTGAGATGTCTTTGGTITC \\
\hline Col-IV, forward & GCTCTGGCTGTGGAAAATGT \\
\hline Col-IV, reverse & CTTGCATCCCGGGAAATC \\
\hline TLR4, forward & GGGAACAAACAGCCTGAGAC \\
\hline TLR4, reverse & AGACCCATGAAATTGGCA T \\
\hline HMG-CoA, forward & AGCCGAAGCAGCACATGAT \\
\hline HMG-CoA, reverse & CTTGTGGAATGCCTTGTGATTG \\
\hline$A B C A 1$, forward & CGTTTCCGGGAAGTGTCCTA \\
\hline$A B C A 1$, reverse & GCTAGAGATGACAAGGAGGATGGA \\
\hline TNF- $a$, forward & CCGATGGGTTGTACCTTGTC \\
\hline TNF- $a$, reverse & GGCAGAGAGGAGGTTGACTIT \\
\hline IL-1 $\beta$, forward & CTCACAAGCAGAGCACAAGC \\
\hline IL-1 $\beta$, reverse & ACGGATTCCATGGTGAAGTC \\
\hline MCP-1, forward & CTGGATCGGAACCAAATGAG \\
\hline MCP-1, reverse & CGGGTCAACTTCACATTCAA \\
\hline NOX4, forward & ATTTGGATAGGCTCCAGGCAAAC \\
\hline NOX4, reverse & CACATGGGTATAAGCTITGTGAGCA \\
\hline IFN- $\gamma$, forward & GCGTCATTGAATCACACCTG \\
\hline IFN- $\gamma$, reverse & TGAGCTCATTGAATGCTTGG \\
\hline HMGB1, forward & AACCTGATGCAGCGAAAAAG \\
\hline HMGB1, reverse & ССТСАТССТСТТСАТССТССТ \\
\hline Oeteopontin, forward & GATGATGATGACGATGGAGACC \\
\hline Osteopontin, reverse & CGACTGTAGGGACGATTGGAG \\
\hline E-cadherin, forward & CAAGGACAGCCTTCTTITCG \\
\hline E-cadherin, reverse & TGGACTTCAGCGTCACTITG \\
\hline FSP-1, forward & ССТCTCTACAACCCCTCTCT- \\
\hline FSP-1, reverse & GGACACCATCACATCCAG \\
\hline a-SMA, forward & CTGACAGAGGCACCACTGAA \\
\hline a-SMA, reverse & CATCTCCAGAGTCCAGCACA \\
\hline$\beta$-Actin, forward & GGACTCCTATGTGGGTGACG \\
\hline$\beta$-Actin, reverse & CTTCTCCATGTCGTCCCAGT \\
\hline
\end{tabular}

Abbreviations: ABCA1, ATP-binding cassette transporter-1; Col-IV, type IV collagen; FSP-1, fibroblast-specific protein 1; GLP-1R, glucargon-like peptide-1 receptor; HMGB1, high-mobility group protein B1; HMG-CoA, 3-hydroxy-3methylglutaryl (HMG)-CoA reductase; IFN- $\gamma$, interferon-gamma; IL-1 $\beta$, interleukin-1 $\beta$; MCP-1, monocyte chemoattractant peptide-1; NOX4, NADPH oxidase 4 ; PAI-1, plasminogen activator inhibitor-1; TGF- $\beta$, transforming growth factor- $\beta$; TLR4, Toll-like receptor 4 ; TNF- $\alpha$, tumor necrosis factor- $\alpha$. In this experiment, each sample was run in triplicate, and the corresponding non-reverse transcribed mRNA samples were used as negative controls. The mRNA level of each sample was normalized to that of $\beta$-actin mRNA. 
LightCycler 1.5 system (Roche Diagnostics, Indianapolis, IN, USA) using SYBR Green technology. Thermocycling conditions consisted of 22-30 cycles of denaturation for $10 \mathrm{~s}$ at $95^{\circ} \mathrm{C}$ followed by annealing and extension for $30 \mathrm{~s}$ at $60^{\circ} \mathrm{C}$. The expression ratio of each gene relative to $\beta$-actin (relative gene expression) was calculated by subtracting the threshold cycle number $(\mathrm{Ct})$ of the target gene from that of $\beta$-actin and raising 2 to the power of this difference.

\section{Protein Extraction and Western Blot Analysis}

Protein extracts were prepared from renal cortical tissue samples and cells using a standard method, and $40 \mu \mathrm{g}$ of protein was electrophoresed on 10\% SDS-PAGE minigels, and the membranes were incubated in blocking buffer overnight at $4{ }^{\circ} \mathrm{C}$ with rabbit polyclonal anti-ATP-binding cassette transporter-1 antibodies (1:200, Abcam Plc), rabbit polyclonal anti-TGF- $\beta 1$ antibodies (1:200; Santa Cruz Biotechnology), goat polyclonal anti-nephrin antibodies (1:500, Santa Cruz Biotechnology), goat polyclonal anti-type I collagen $\alpha 1$ antibodies (1:2000, Abcam Plc), goat polyclonal anti-3-hydroxy-3-methylglutaryl-coenzyme A (anti-HMGCoA) reductase antibodies (1:100, Santa Cruz Biotechnology), rabbit polyclonal anti-osteopontin antibodies (1:1000, Abcam $\mathrm{Plc}$ ), goat polyclonal anti-E-cadherin antibodies (1:500,
Abcam Plc), rabbit polyclonal anti-FSP-1 antibodies (1:200, Abcam Plc) and mouse monoclonal anti- $\beta$-actin antibodies (1:5000, Sigma-Aldrich). The membranes were subsequently incubated with horseradish peroxidase-conjugated secondary antibodies (1:1000 dilution) for $60 \mathrm{~min}$ at room temperature. Immunoreactive bands were detected using enhanced chemiluminescence reagents (Amersham, Buckinghamshire, UK).

\section{Immunofluorescence Microscopy for DPPIV}

To confirm the presence of DPPIV in cultured podocytes, immunofluorescence staining was performed for CD26 (DPPIV). Podocytes were grown in a four-chambered glass slide and then fixed at RT for $10 \mathrm{~min}$ in $75 \%$ ethanol. The slides were incubated at $4{ }^{\circ} \mathrm{C}$ overnight with rabbit polyclonal anti-CD26 antibodies (1:500; Abcam Plc) in a solution containing $0.2 \%$ Triton X-100. Nuclei were counterstained with DAPI. After rinsing in ice-cold PBS, slides were incubated with fluorescent-labeled (Alexa Fluor 488-conjugated) donkey anti-rabbit IgG secondary antibodies (1:200; Invitrogen, Carlsbad, CA, USA) for $1 \mathrm{~h}$ at $37^{\circ} \mathrm{C}$.

\section{In Vitro DPPIV Activity Experiments}

The mouse podocyte cell line was obtained from Peter Mundel at the Albert Einstein College of Medicine, NY, USA.
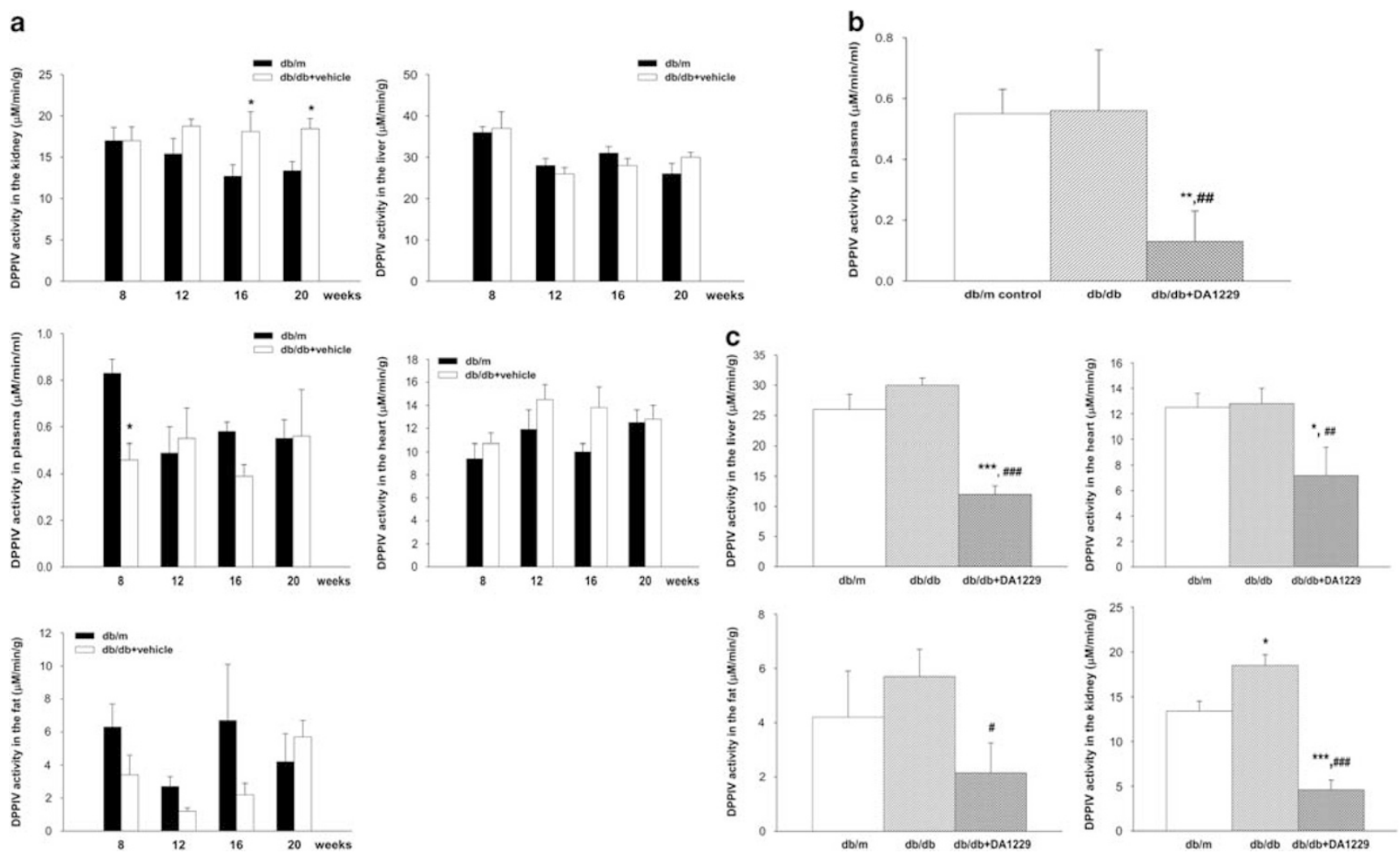

Figure 1 Time course of DPPIV activity in various organs and effects of DA-1229 on DPPIV activity. (a) DPPIV activity in plasma and various organs over time. (b) DPPIV activity in the plasma after 3 months of treatment with DA-1229. (c) DPPIV activity in various organs after 3 months of treatment with DA-1229. Values are expressed as means \pm s.e.m. Statistical analysis was performed between different groups at the same time points. ${ }^{*} P<0.05$, ${ }^{* *} P<0.01,{ }^{* *} P<0.001$ vs $d b / m$ group; ${ }^{\#} P<0.05,{ }^{\# \#} P<0.01$, ${ }^{\# \# \#} P<0.001$ vs $d b / d b$ group. 
Cells were cultured in RPMI medium supplemented with $10 \%$ FCS. To evaluate the effect of high glucose and angiotensin II stimulation on DPPIV activity, subconfluent cells were serum starved for $24 \mathrm{~h}$. Then medium was replaced with fresh medium containing $30 \mathrm{mM}$ D-glucose and/or $100 \mathrm{nM}$ angiotensin II and cultured for $72 \mathrm{~h}$, and harvested for measurement of DPPIV activity. To test the effects of DPPIV activity on macrophage infiltration, cells were treated

Table 2 Physical and biochemical parameters in $d b / d b$ mice

\begin{tabular}{|c|c|c|c|c|}
\hline Parameter & Week & $\mathrm{db} / \mathrm{m}$ & $\mathrm{db} / \mathrm{db}+$ vehicle & $\mathrm{db} / \mathrm{db}+\mathrm{DA}-1229$ \\
\hline \multirow[t]{4}{*}{ Body weight (g) } & 0 & $24.3 \pm 0.5$ & $36.1 \pm 1.0^{*}$ & $37.3 \pm 0.8^{*}$ \\
\hline & 4 & $27.4 \pm 1.2$ & $47.2 \pm 2.0^{*}$ & $49.6 \pm 2.5^{*}$ \\
\hline & 8 & $30.7 \pm 0.9$ & $54.9 \pm 1.2^{*}$ & $51.4 \pm 3.3^{*}$ \\
\hline & 12 & $33.5 \pm 1.1$ & $58.9 \pm 2.1^{*}$ & $57.2 \pm 2.5^{*}$ \\
\hline \multirow[t]{4}{*}{ Daily food intake (g) } & 0 & $2.36 \pm 0.14$ & $5.44 \pm 0.34^{*}$ & $5.31 \pm 0.28^{*}$ \\
\hline & 4 & $3.36 \pm 0.04$ & $7.42 \pm 0.09^{*}$ & $6.75 \pm 0.34^{*}$ \\
\hline & 8 & $3.90 \pm 0.15$ & $7.15 \pm 0.09^{*}$ & $6.62 \pm 0.15^{*}$ \\
\hline & 12 & $3.02 \pm 0.27$ & $6.01 \pm 0.03^{*}$ & $5.67 \pm 0.08^{*}$ \\
\hline \multirow[t]{4}{*}{ Daily water intake (g) } & 0 & $5.5 \pm 0.3$ & $12.9 \pm 0.6^{*}$ & $10.7 \pm 1.4^{*}$ \\
\hline & 4 & $4.6 \pm 0.2$ & $14.8 \pm 0.5^{*}$ & $11.6 \pm 0.8^{*}$ \\
\hline & 8 & $4.7 \pm 0.1$ & $15.1 \pm 0.0^{*}$ & $15.1 \pm 0.3^{*}$ \\
\hline & 12 & $4.1 \pm 0.2$ & $16.8 \pm 0.4^{*}$ & $8.6 \pm 0.4^{\ddagger, \S}$ \\
\hline \multirow[t]{4}{*}{ Fasting blood glucose (mg/dl) } & 0 & $163 \pm 15$ & $248 \pm 13$ & $12.1 \pm 0.9$ \\
\hline & 4 & $190 \pm 11$ & $472 \pm 43^{*}$ & $27.3 \pm 1.5^{*}$ \\
\hline & 8 & $168 \pm 6$ & $458 \pm 22^{*}$ & $23.2 \pm 1.9^{*}$ \\
\hline & 12 & $153 \pm 6$ & $562 \pm 53^{*}$ & $466 \pm 66^{\S}$ \\
\hline \multirow[t]{4}{*}{ Urine volume (ml/day) } & 0 & $0.30 \pm 0.09$ & $0.42 \pm 0.07$ & $0.51 \pm 0.04^{*}$ \\
\hline & 4 & $0.23 \pm 0.05$ & $1.84 \pm 0.28^{*}$ & $1.64 \pm 0.34^{*}$ \\
\hline & 8 & $0.19 \pm 0.02$ & $1.04 \pm 0.16^{\dagger}$ & $1.30 \pm 0.80^{*}$ \\
\hline & 12 & $0.21 \pm 0.02$ & $1.25 \pm 0.36^{\ddagger}$ & $1.07 \pm 0.29^{\ddagger}$ \\
\hline \multirow[t]{4}{*}{ HbA1c (\%) } & 0 & $3.32 \pm 0.84$ & $6.18 \pm 0.19^{\ddagger}$ & $6.28 \pm 0.41^{\ddagger}$ \\
\hline & 4 & $4.56 \pm 0.09$ & $8.90 \pm 0.36^{*}$ & $8.72 \pm 0.36^{*}$ \\
\hline & 8 & $4.50 \pm 0.18$ & $9.90 \pm 0.37^{*}$ & $9.73 \pm 0.74^{*}$ \\
\hline & 12 & $5.14 \pm 0.19$ & $9.21 \pm 0.43^{*}$ & $8.58 \pm 0.79^{*}$ \\
\hline Kidney per $100 \mathrm{~g}$ BW & 12 & $0.89 \pm 0.07$ & $0.82 \pm 0.04$ & $0.64 \pm 0.08^{\dagger}$ \\
\hline Heart per $100 \mathrm{~g}$ BW & 12 & $0.44 \pm 0.03$ & $0.25 \pm 0.09^{*}$ & $0.23 \pm 0.09$ \\
\hline Fat per $100 \mathrm{~g} \mathrm{BW}$ & 12 & $2.50 \pm 0.29$ & $4.58 \pm 0.27^{*}$ & $4.31 \pm 0.42^{*}$ \\
\hline Liver per $100 \mathrm{~g}$ BW & 12 & $3.97 \pm 0.09$ & $5.25 \pm 0.33^{\dagger}$ & $6.06 \pm 0.29$ \\
\hline P-adiponectin ( $\mu \mathrm{g} / \mathrm{ml})$ & 12 & $16.36 \pm 1.24$ & $11.02 \pm 1.32^{\ddagger}$ & $8.38 \pm 1.25^{\ddagger}$ \\
\hline P-creatinine $(\mu \mathrm{mol} / \mathrm{l})$ & 12 & $35.0 \pm 4.0$ & $45.0 \pm 6.0$ & $29.0 \pm 2.0^{\natural}$ \\
\hline HOMA-IR & 12 & $0.42 \pm 0.20$ & $4.04 \pm 1.08^{\ddagger}$ & $4.45 \pm 1.64^{\ddagger}$ \\
\hline Active GLP-1 level (pM) & 12 & $10.83 \pm 0.26$ & $11.84 \pm 0.71$ & $21.12 \pm 2.48^{\natural}$ \\
\hline $\mathrm{SBP}(\mathrm{mmHg})$ & 12 & $118 \pm 16$ & $115 \pm 15$ & $124 \pm 11$ \\
\hline P-MCP-1 (pg/ml) & 12 & $12.4 \pm 2.3$ & $36.7 \pm 3.6^{*}$ & $17.2 \pm 2.1^{\natural}$ \\
\hline P-8-isoprosatne (pg.ml) & 12 & $316 \pm 39$ & $978 \pm 177^{\dagger}$ & $563 \pm 65^{\S}$ \\
\hline U-8-isoprostane ( $\mathrm{ng} / \mathrm{mgCr}$ ) & 12 & $2.83 \pm 0.34$ & $13.27 \pm 3.14^{*}$ & $7.65 \pm 1.68^{\S}$ \\
\hline
\end{tabular}

Abbreviations: MCP-1, monocyte chemoattractnet peptide-1; $\mathrm{P}$, plasma.; $\mathrm{U}$, urine. Values are expressed as means $\pm \mathrm{s}$.e.m. Statistical analysis was performed between different groups at the same time points. ${ }^{\dagger} P<0.05,{ }^{\ddagger} P<0.01,{ }^{*} P<0.001 \mathrm{vs} d b / \mathrm{m}$ control; ${ }^{\S} P<0.05$, ${ }^{\mathbb{9}} P<0.01 \mathrm{vs} d b / d b+$ vehicle. 
with $30 \mathrm{mM}$ D-glucose and $100 \mathrm{nM}$ of angiotensin II with or without prior treatment with DA-1229 (10 nM) for $72 \mathrm{~h}$, and evaluated the relationship between changes of representative macrophage chemoattractant proteins such as MCP-1 and osteopontin and DPPIV activity. To test the effects of various inhibitors on DPPIV activity, cells were cultured in the presence of 1,10 and $100 \mathrm{nM}$ of each drug for $72 \mathrm{~h}$. To determine the effect of inhibiting DPPIV on nephrin production, DA-1229 (10 $\mathrm{nM})$ was added to cells $60 \mathrm{~min}$ before treatment with high glucose and angiotensin II. All experiments were performed with three technical replicates.

\section{Cell Viability Assay (3-[4,5-Dimethylthiozol]-2,5- Diphenyl Tetrazolium Bromide Assay)}

A modified colorimetric assay was used to quantify cell viability. Briefly, confluent cells were cultivated on 96-well tissue culture plates and made quiescent in serum-deprived conditions for $24 \mathrm{~h}$. Cells were then incubated for 24, 48 and $72 \mathrm{~h}$ in high glucose medium ( $30 \mathrm{mM}$ D-glucose) with or without DA-1229 $(10 \mathrm{nM})$. The solubilized formazan product was then measured in an ELISA at $570 \mathrm{~nm}$.

\section{Statistical Analysis}

Nonparametric analysis was performed because of the relatively small number of samples. Results are expressed as means \pm s.e.m. For the adriamycin nephropathy data, Student's $t$-test and the paired $t$-test were performed to determine the significance of differences between two groups and between time points in the same group, respectively. Data from the $d b / d b$ mice were analyzed with the Wilcoxon rank-sum test followed by the Bonferroni correction. The Kruskal-Wallis test was used to compare $>2$ groups, followed by the Mann-Whitney $U$-test. Correlations between DPPIV activity levels and supernatant MCP-1 levels were examined using Spearman's correlation analysis. P-values $<0.05$ were considered statistically significant. Statistical analyses were performed using SPSS for Windows, version 12.0 (SPSS, Chicago, IL, USA).

\section{RESULTS}

\section{Kinetics of DPPIV Activity in Diabetic Mice}

The levels of DPPIV activity over time in the plasma and various organs of nondiabetic $v s$ diabetic mice are shown in Figure 1. DPPIV activity was significantly higher in kidneys
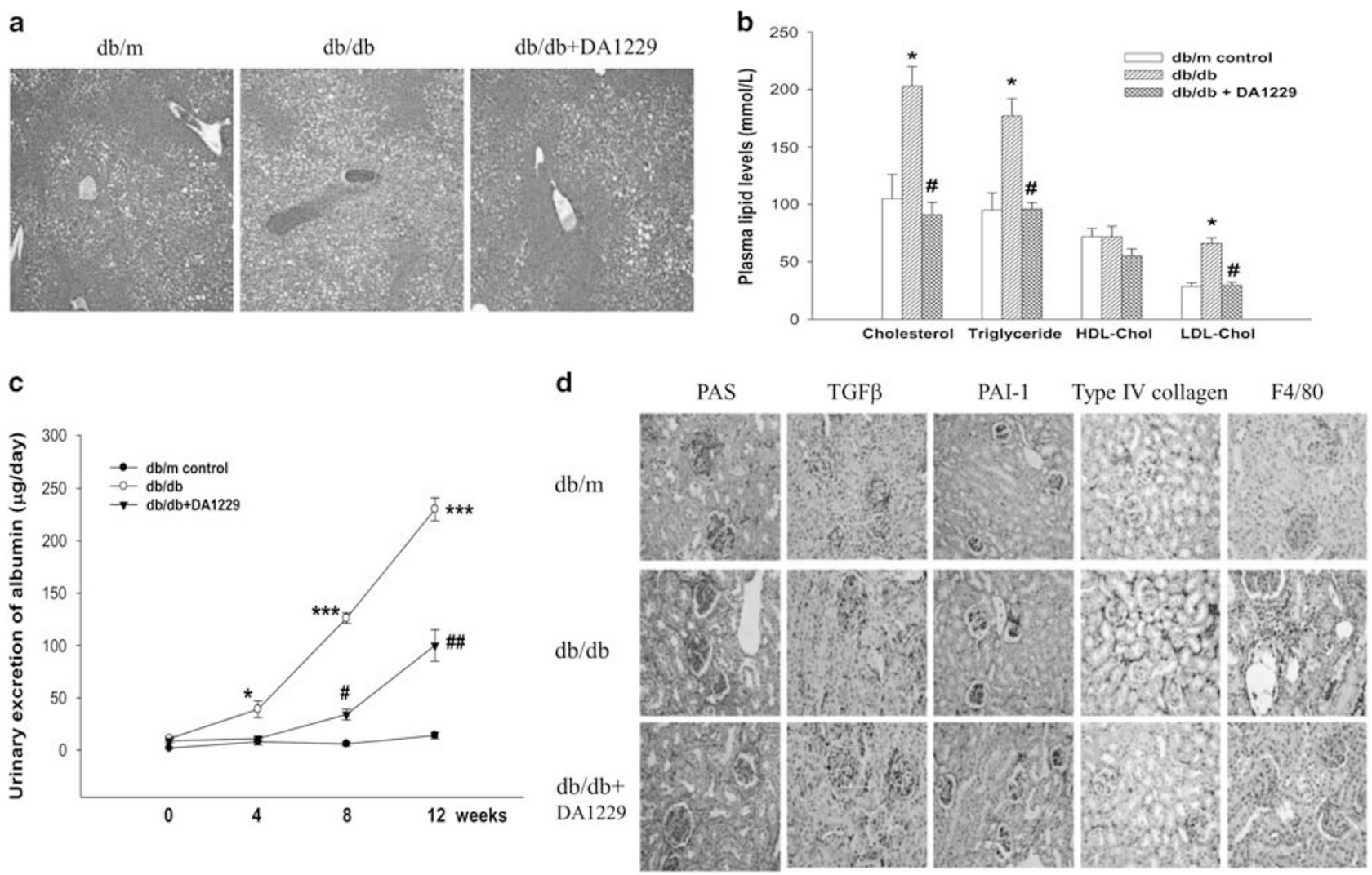

Figure 2 Effects of DA-1229 on plasma lipid concentration, urinary albumin excretion, liver histology and kidney histology. (a) Representative liver histological findings. (b) Lipid parameters after 3 months of treatment with DA-1229. (c) Effect of DA-1229 on $24-\mathrm{h}$ urinary albumin excretion. (d) Representative renal histological findings after 3 months of treatment with DA-1229. Values are expressed as means \pm s.e.m. Original magnification $x 400$. Statistical analysis was performed between different groups at the same time points. ${ }^{*} P<0.05$, ${ }^{* * *} P<0.001 \mathrm{vs} d b / \mathrm{m}$ group; ${ }^{\sharp} P<0.05,{ }^{\# \#} P<0.01 \mathrm{vs} d b / d b$ group. 
from diabetic mice than nondiabetic mice at the late stage of disease. However, DPPIV activity in the plasma and other organs was not significantly different between the two groups at this stage (Figure 1a). Interestingly, DA-1229 treatment markedly suppressed DPPIV activity in the plasma and all organs tested, including the kidney (Figures $1 \mathrm{~b}$ and c).

\section{Effects of DA-1229 on Physical and Metabolic Parameters in $\mathbf{~ d b / d b}$ Mice}

The biochemical and physical parameters tested are shown in Table 2. The mean fasting blood glucose level, HbAlc level, body weight, urine volume, water and food intake, HOMA-IR, fat mass per body weight, and liver mass per body weight were all significantly higher in diabetic $d b / d b$ mice than nondiabetic $d b / m$ mice. In contrast, the mean plasma level of adiponectin was significantly lower in diabetic $d b / d b$ mice. Interestingly, DA-1229-treated $d b / d b$ mice showed a significantly reduced water intake, fasting blood glucose level and plasma concentration of creatinine compared with vehicle-treated $d b / d b$ mice. However, no significant differences were observed regarding body weight, food intake, urine volume, tissue weight, HbAlc, HOMA-IR, systolic blood pressures or plasma adiponectin level between the two groups. In addition, no significant differences were observed between the two groups regarding glucose tolerance or insulin resistance, as determined by the oral GTT and the ITT (data not shown). Although the levels of active GLP-1 were not significantly different between diabetic $d b / d b$ mice and nondiabetic $d b / m$ mice, DA-1229 treatment significantly increased the level of active GLP-1 in both groups. In addition, plasma and urinary levels of inflammatory and oxidative stress markers such as MCP-1 and 8-isoprostane were significantly increased in diabetic $d b / d b$ mice than those in nondiabetic $d b / m$ mice. DA-1229 treatment significantly improved plasma and urinary levels of inflammatory and oxidative stress markers (Table 2). Interestingly, the DA-1229-treated group exhibited improved hepatic steatosis (Figure 2a). In accordance with these changes, the plasma lipid profiles were significantly improved by DA-1229 treatment as compared with vehicle-treated $d b / d b$ mice (Figure $2 \mathrm{~b}$ ).

\section{Effects of DA-1229 Treatment on Kidney Function and Structure}

Throughout the duration of the experiment, urinary albumin excretion was significantly increased in $d b / d b$ mice compared with $d b / m$ mice. This increased albuminuria was significantly attenuated by 8 weeks of DA-1229 treatment, and this decrease was maintained until 12 weeks of treatment
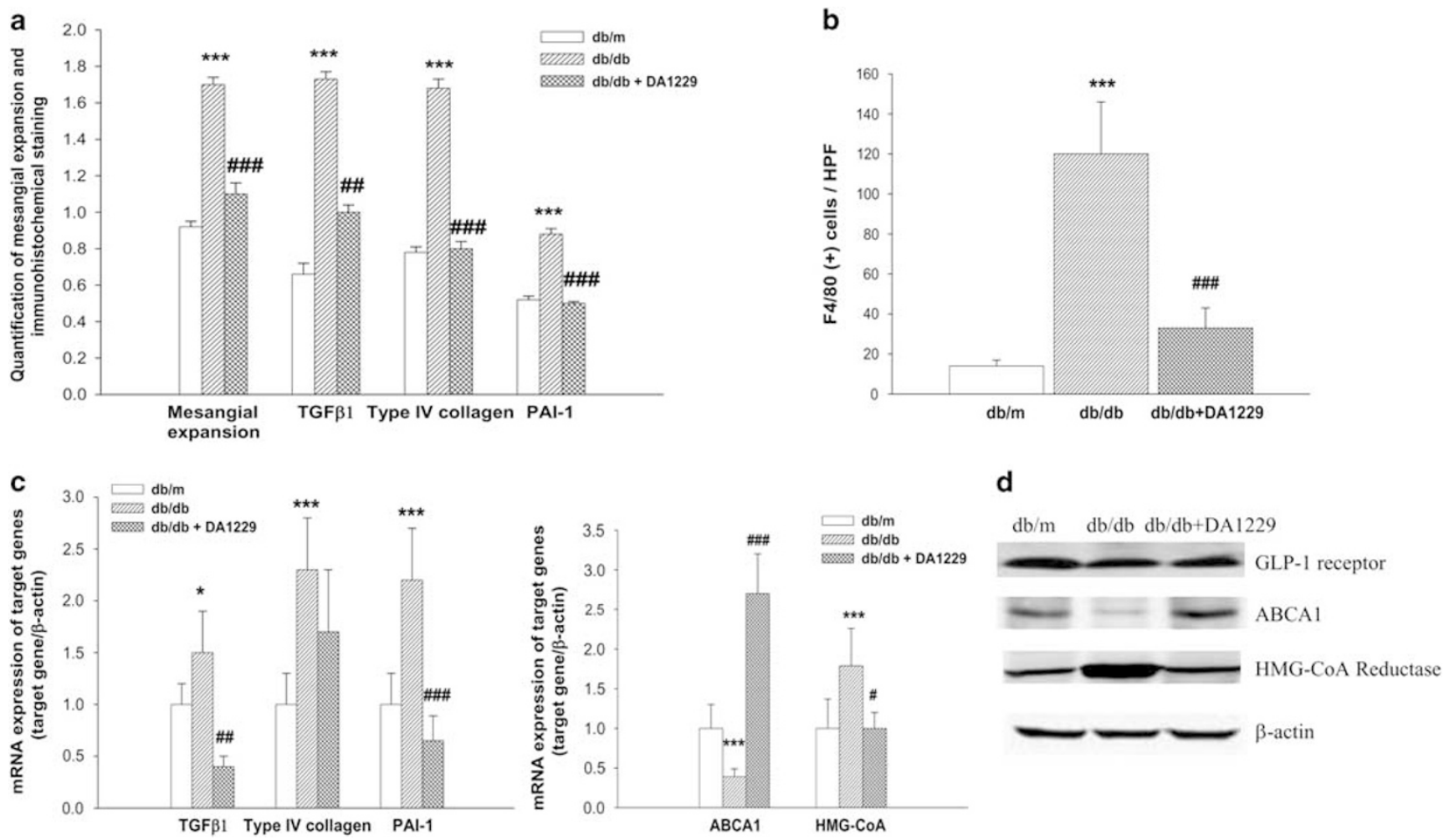

Figure 3 Effects of DA-1229 on profibrotic and proinflammatory molecules in renal cortical tissue. (a) Glomerular mesangial expansion scores and immunostaining scores. (b) Effect of DA-1229 on macrophage infiltration. (c) mRNA expression in renal cortical tissue. (d) Representative western blot showing expression of the GLP-1 receptor, ABCA1 and HMG-CoA reductase in renal cortical tissue. Values are expressed as means \pm s.e.m. ${ }^{*} P<0.05$,

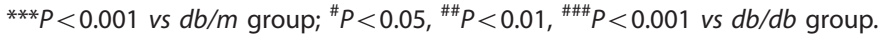


a
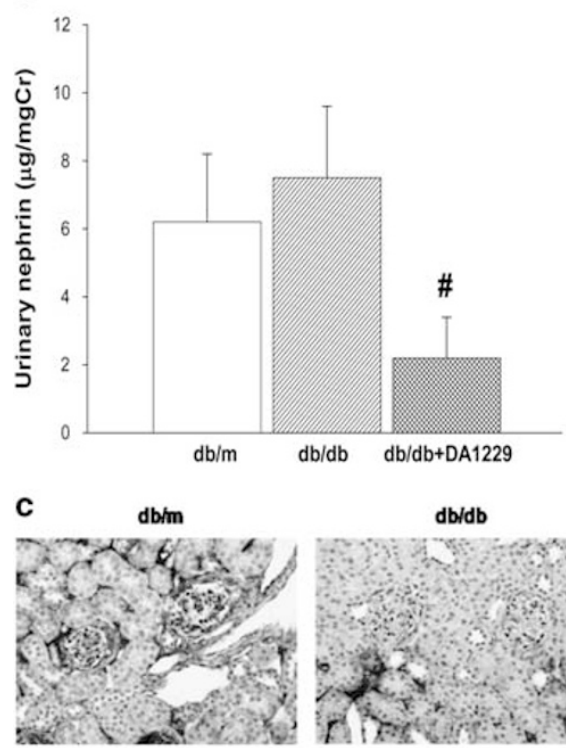

$d b / d b$
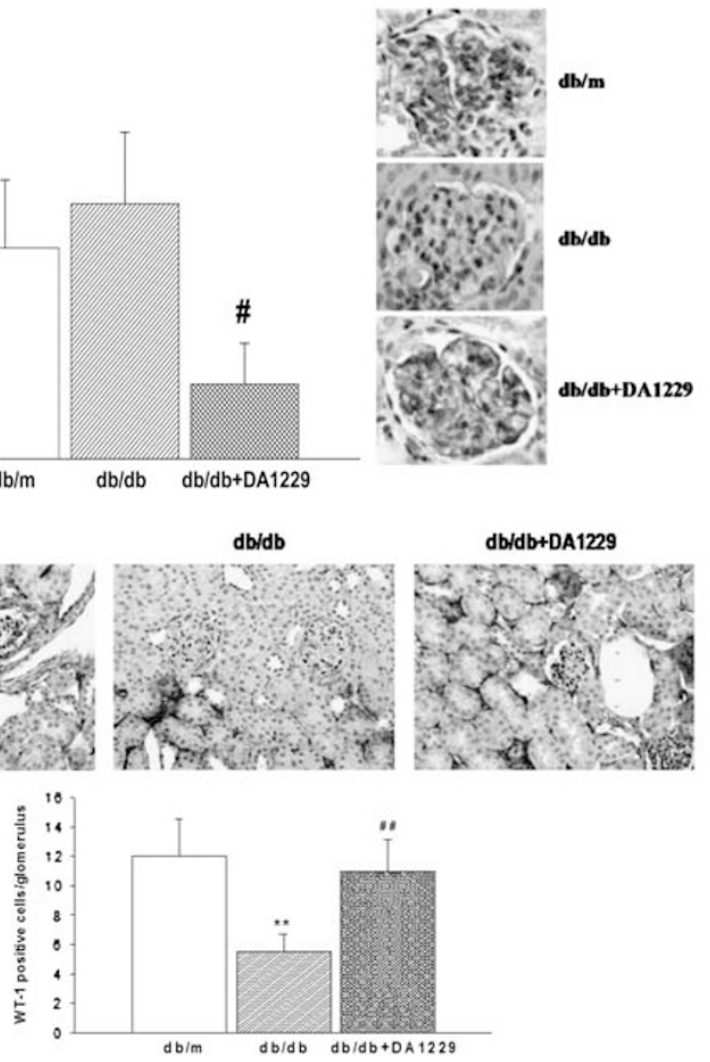

b

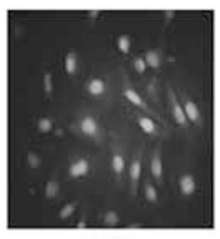

CD26

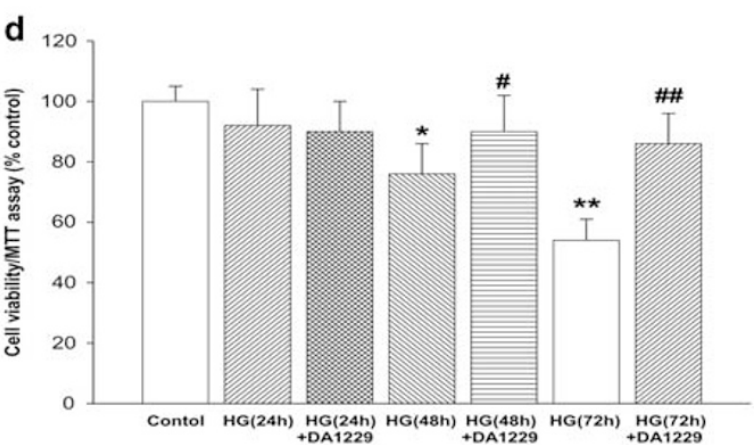

e NG $\quad H G+A n g-\|H G+A n g-\| \quad H G+A n g-\|\quad H G+A n g-\| \quad H G+A n g-\|$ +DA1229 +Linagliptin +Saxagliptin +Sitagliptin
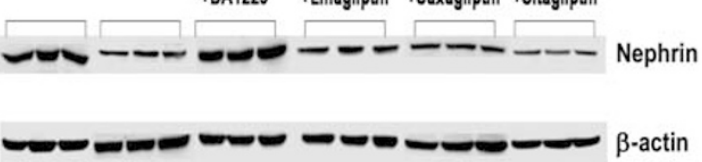

Figure 4 Effects of DA-1229 on urinary excretion of nephrin and cell viability in cultured podocytes. (a) Urinary nephrin excretion after 3 months of treatment with DA-1229 and representative glomerular immunohistochemical staining for nephrin (original magnification $\times 1000 ;{ }^{\#} P<0.05 \mathrm{vs} d b / d b$ group). (b) Representative immunofluorescence staining for CD26 and DAPI staining in cultured podocytes. (c) Representative immunostaining for WT-1 and immunostaining score after 3 months of treatment with DA-1229. (d) Effect of high glucose and DA-1229 on cell viability in cultured podocytes. (e) Representative western blot showing the effects of various DPPIV inhibitors on nephrin expression. Ang-ll, angiotensin II (100 nM); HG, high glucose (30 mM); NG, normal glucose $(5 \mathrm{mM})$. Values are expressed as means \pm s.e.m. ${ }^{*} P<0.05$, ${ }^{* *} P<0.01 \mathrm{vs}$ control (NG) or $d b / \mathrm{m}$ group; ${ }^{\#} P<0.05$, ${ }^{\# \#} P<0.01 \mathrm{vs}$ HG or $d b / d b$ group.

(Figure 2c). In addition, histological sections of kidneys from DA-1229 treatment showed significantly attenuated glomerular tuft hypertrophy, mesangial expansion and macrophage infiltration (Figure 2d). Consistent with these histological changes, immunohistochemical staining score and the mRNA expression levels revealed that the levels of profibrotic markers and macrophage infiltration were significantly ameliorated by DA-1229 treatment (Figures $3 \mathrm{a}$ and $\mathrm{c}$ ). However, the renal expression of the GLP-1 receptor was not significantly different between the two groups (Figure 3d). Interestingly, the expression of HMG-CoA reductase was markedly downregulated by DA- 1229 treatment. On the other hand, the expression of adenosine triphosphate-binding cassette transporter A1 (ABCA1) was significantly upregulated by DA-1229 treatment (Figures $3 \mathrm{c}$ and d).

\section{Effects of DA-1229 on Urinary Excretion of Nephrin and Podocyte Injury}

As shown in Figure 4a, DA-1229 treatment markedly decreased urinary excretion of nephrin. Moreover, nephrin expression was markedly downregulated in $d b / d b$ mice compared with $d b / m$ mice, whereas DA-1229 treatment restored nephrin expression. Next, we investigated the expression of DPPIV in untreated (basal state) podocytes by IF and found that DPPIV exhibited a cytoplasmic distribution (Figure $4 \mathrm{~b}$ ). To more clearly determine the cause of decreased urinary excretion of nephrin after DA-1229 treatment, we next investigated the effect of DA-1229 on podocyte loss by performing immunostaining with WT-1 and cell viability assay. As shown in Figure 4c, numbers of WT-1-positivestained cells in the glomeruli were significantly increased in DA-1229 treatment group compared with that in $d b / d b$ mice group. In addition, we also observed that DA-1229 pretreatment significantly increased podocyte survival from high glucose-induced cytotoxic injury using MTT assay (Figure 4d). Next, we determined the effect of inhibiting DPPIV on nephrin synthesis in podocytes. Interestingly, stimulation with high glucose and angiotensin II markedly reduced the cellular level of nephrin, whereas treatment with DA-1229 most effectively restored nephrin production (Figure 4e). 

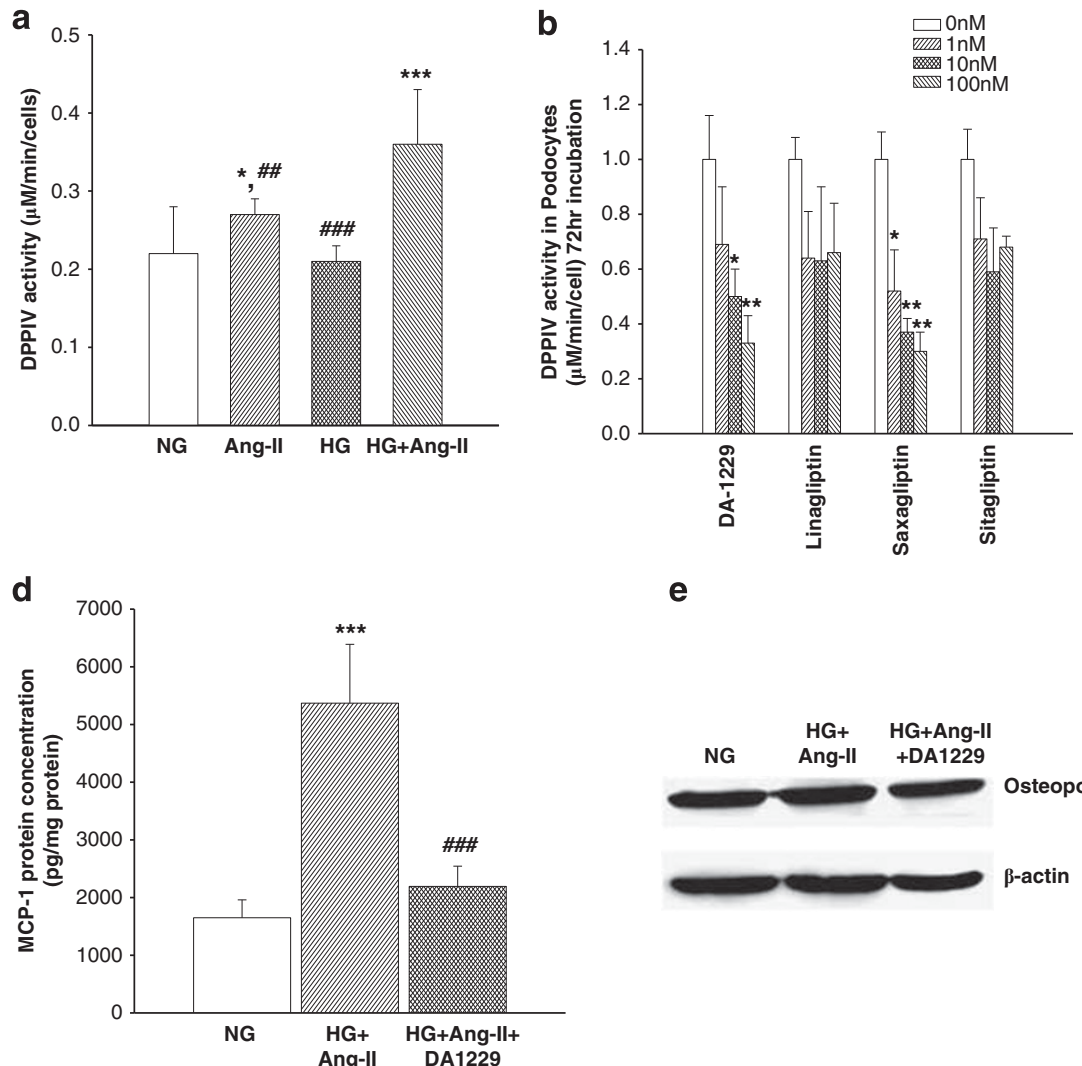

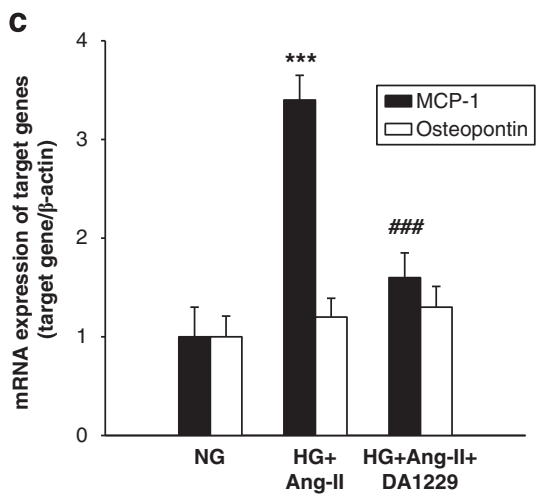

e

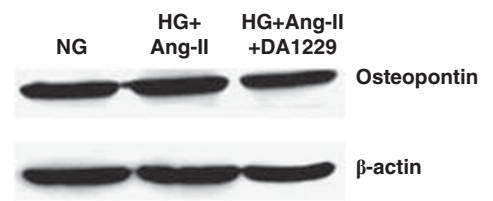

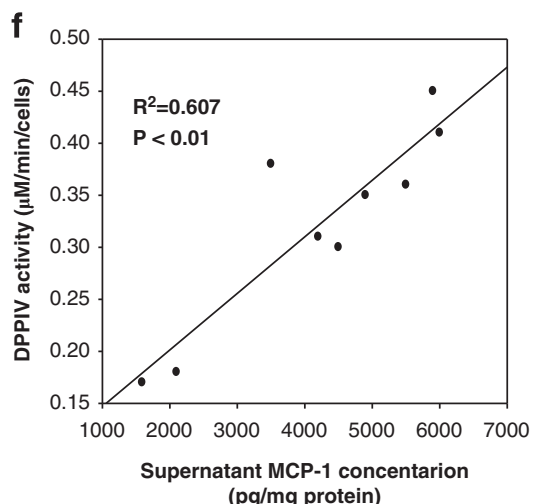

f (pg/mg protein)

Figure 5 Effects of high glucose and angiotenin II stimulation on DPPIV activity and relationship between DPPIV activity and MCP-1 production in cultured podocytes. (a) Effects of high glucose and angiotensin II on DPPIV activity in cultured podocytes $\left({ }^{*} P<0.05,{ }^{* * *} P<0.001\right.$ vs NG; ${ }^{\# \#} P<0.01$, $\# \# \#<0.001$ vs $\mathrm{HG}+$ Ang-II). (b) Effects of various DPPIV inhibitors on DPPIV activity in cultured podocytes $\left({ }^{*} P<0.05,{ }^{* *} P<0.01\right.$ vs $\left.0 \mathrm{nM}\right)$. (c) Effects of high

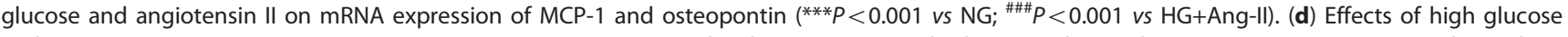
and angiotensin II on MCP-1 protein secretion. Supernatant MCP-1 levels were expressed relative to the total protein concentration in each condition and expressed as MCP-1 (pg/mg protein) ( ${ }^{* *} P<0.001$ vs NG; ${ }^{\# \# \# P<0.001 ~ v s ~ H G+A n g-I I) . ~(e) ~ R e p r e s e n t a t i v e ~ w e s t e r n ~ b l o t ~ f o r ~ o s t e o p o n t i n . ~(f) ~ C o r r e l a t i o n ~}$ analysis between supernatant MCP-1 levels and DPPIV activity. Values are expressed as means \pm s.e.m. Ang-ll, angiotensin II (100 nM); HG, high glucose (30 mM); NG, normal glucose $(5 \mathrm{mM})$.

\section{Effects of DA-1229 on DPPIV Activity and Chemoattractant Protein Synthesis in Cultured Podocytes}

We then evaluated whether high glucose and angiotensin II, two major mediators of DN, affect DPPIV activity in podocytes. Although no significant changes in DPPIV activity were observed after stimulation with high glucose, angiotensin II significantly increased DPPIV activity and stimulation with both high glucose and angiotensin II additively increased DPPIV activity in podocytes (Figure 5a). Regarding the potencies of the various DPPIV inhibitors, DA-1229 and saxagliptin were the strongest inhibitors of all drugs tested, with DA-1229 reducing DPPIV activity by $50 \%$ when used at $10 \mathrm{nM}$ (Figure 5b). As DA-1229 significantly decreased macrophage infiltration in the kidney, we next examined whether increased DPPIV activity induced upregulation of chemoattractant proteins such as MCP-1 and osteopontin. As shown in Figures $5 c$ and e, high glucose and angiotensin II stimulation markedly increased MCP-1 gene expression and MCP-1 protein secretion in cultured podocyte. However, there was no significant change in osteopontin expression after stimulation with high glucose and angiotensin II. Furthermore, there was a significant positive correlation between DPPIV activity and supernatant MCP-1 levels in cultured podocytes (Figure 5f).

\section{Effects of DA-1229 on DPPIV Activity and Renal Injury in the Adriamycin Model}

As DA-1229 significantly suppressed DPPIV activity and restored nephrin expression in cultured podocytes, we further examined the effects of DA-1229 on podocyte injury in adriamycin mice. Although plasma DPPIV activity was not significantly different in adriamycin mice compared with control mice, DPPIV activity in the kidney was significantly higher in the adriamycin mice (Figure 6a). In addition, DA-1229 markedly decreased plasma and renal DPPIV activity when given both preventively and therapeutically to adriamycin mice (Figures $6 \mathrm{~b}$ and $\mathrm{c}$ ). However, no significant differences in the levels of active GLP-1 were observed among the groups (Figure 6d). In addition, urinary excretion 

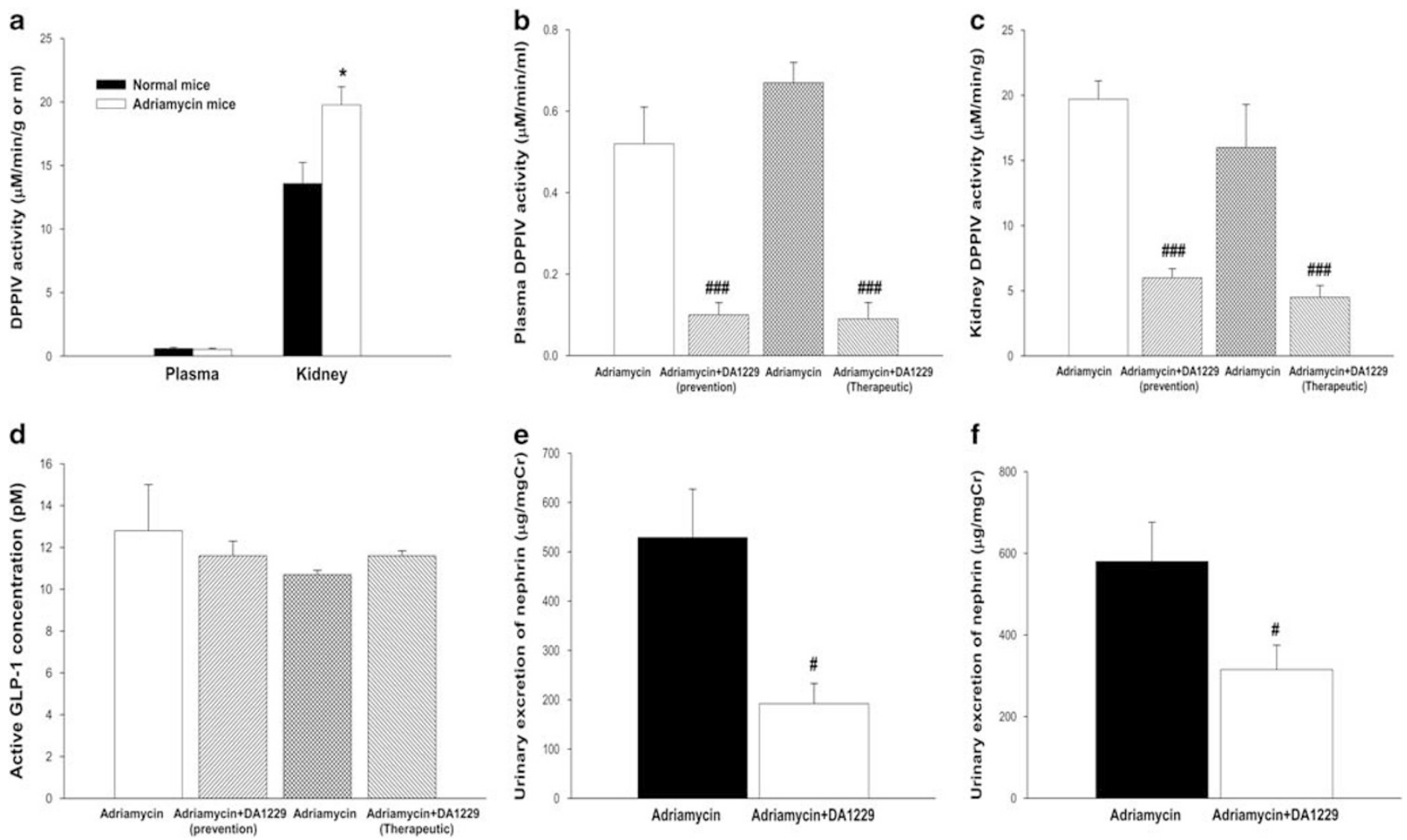

Figure 6 Effects of DA-1229 on DPPIV activity in the plasma and kidneys and urinary excretion of nephrin in the adriamycin-induced nephrotoxicity model. (a) DPPIV activity in the plasma and kidneys. (b) Effects of preventive and therapeutic DA-1229 on plasma DPPIV activity. (c) Effects of DA-1229 on renal DPPIV activity. (d) Concentrations of active GLP-1. (e, f) Urinary excretion of nephrin in the model of adriamycin-induced nephrotoxicity. Values

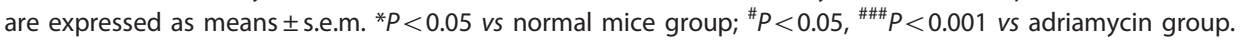

of nephrin was markedly decreased in both the preventive and therapeutic groups of adriamycin mice (Figures 6e and $\mathrm{f}$.

\section{Effects of DA-1229 on Plasma and Urinary Inflammatory Molecules in Adriamycin Mice}

As DPP4 inhibitor has shown to decrease proinflammatory cytokines and atherosclerotic process in both diabetic patients and animal models of diabetes independent of the effects on the glycemic controls, we also measured plasma and urinary levels of inflammatory and oxidative stress markers such as MCP-1 and 8-isoprostane in adriamycin model. Similar to the results in diabetic mice, DA-1229 treatment significantly decreased plasma and urinary levels of inflammatory and oxidative stress markers (Figure 7).

\section{Effects of DA-1229 on Renal Structural and Functional Changes in Adriamycin Mice}

The renal pathology and immunostaining of F4/80, $\alpha$-SMA and nephrin in DA-1229-treated and -untreated mice are shown in Figure 8a. PAS and $\alpha$-SMA immunostaining revealed extensive glomerulosclerosis, interstitial fibrosis and tubular atrophy in untreated adriamycin mice. Interestingly, both the preventative and therapeutic groups of DA-1229-treated mice significantly decreased macrophage infiltration (Figures $8 \mathrm{a}$ and $\mathrm{c}$ ). In addition, numbers of WT-1-positivestained cells in the glomeruli were significantly increased in DA-1229 treatment group compared with that in adriamycin group (Figure $8 \mathrm{~b}$ ). In accordance with the morphological alterations observed in the kidneys of adriamycin mice, the renal mRNA expression levels of proinflammatory and profibrotic cytokines were remarkably decreased with DA-1229 treatment (Figures 8d and e). In accordance with these changes, DA-1229-treated mice abolished glomerulosclerosis and interstitial fibrosis in both the preventative and therapeutic groups (Figures $9 \mathrm{a}$ and $\mathrm{b}$ ). Proteinuria and albuminuria persistently increased after adriamycin administration, whereas both preventive and therapeutic DA-1229 treatment significantly prevented adriamycin-induced changes (Figures $9 \mathrm{c}$ and $\mathrm{f}$ ). In agreement with these observations, the renal expression of fibrotic proteins such as type I collagen and TGF- $\beta_{1}$ was markedly downregulated by both preventive and therapeutic treatment with DA-1229 (Figure 9g). As DA-1229 treatment markedly suppressed fibrotic process in the kidney, we next observed whether DA-1229 may contribute to the process of epithelialmesenchymal transition (EMT). However, we did not find any significant changes in the representative markers of EMT 

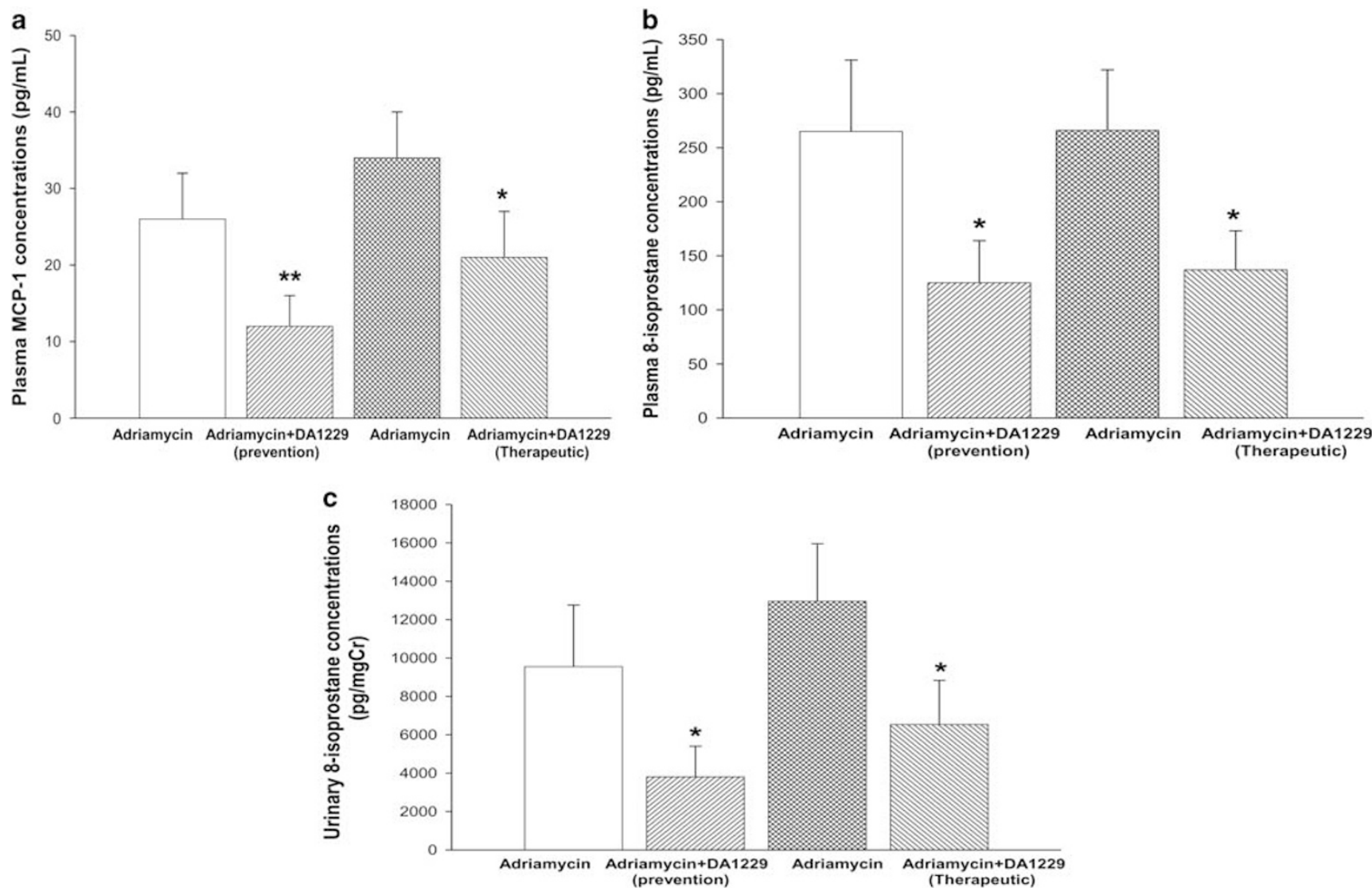

Figure 7 Effects of DA-1229 on inflammatory molecules in the plasma and urinary excretion of 8-isoprostane in the adriamycin-induced nephrotoxicity model. (a) Plasma levels of MCP-1 in experimental animals. (b) Plasma levels of 8-isoprostane in experimental animals. (c) Urinary excretion of 8isoprostane in experimental animals. Values are expressed as means \pm s.e.m. ${ }^{*} P<0.05,{ }^{* *} P<0.01$ vs adriamycin group.

such as loss of E-cadherin and gain of FSP1 and $\alpha$-SMA (Supplementary Figure 1).

\section{DISCUSSION}

In this study, we demonstrated that a novel DPPIV inhibitor, DA-1229, exhibits renoprotective effects. These effects include significantly decreasing urinary albumin excretion, improving renal histological changes and lipid metabolism, and reducing macrophage infiltration in the kidney. Of particular note, we also found that DA-1229-mediated inhibition of DPPIV restored nephrin expression in podocytes and decreased podocyte injury in both $d b / d b$ and adriamycin mice.

DA-1229 is currently in late-stage development for the treatment of type 2 diabetes. This molecule is a reversible and competitive inhibitor of DPPIV, with an inhibitory activity almost 6000-fold more selective for human DPP4 compared with human DPP8 or DPP9. ${ }^{25}$ In streptozotocin-induced diabetic mice, DA-1229 has been shown to significantly reduce plasma DPPIV activity, enhance glucagon-like peptide-1 levels and improve insulin tolerance. ${ }^{26}$ In high-fat diet-induced obese mice, long-term treatment with DA-1229 resulted in significantly improved glucose intolerance and insulin resistance. ${ }^{27}$ In a phase I study performed in 72 healthy Korean male volunteers, each of whom received a single administration of DA-1229 ranging from 1.25 to $60 \mathrm{mg}$, DPPIV inhibition was found to be dose dependent, with groups receiving $\geq 10 \mathrm{mg}$ exhibiting $>80 \%$ DPPIV inhibition for $>24 \mathrm{~h}^{28}$

In this study, we first observed DPPIV activity in the plasma and various target organs over time in diabetic mice. DPPIV activity was not significantly different in the plasma, hepatic tissue, cardiac tissue or adipose tissue of diabetic mice compared with control mice. However, DPPIV activity was significantly higher in the kidneys of diabetic mice compared with their nondiabetic controls. These results are consistent with recent reports that DPPIV expression is upregulated in human renal glomerular epithelial cells during inflammation ${ }^{29}$ and in a rat model of type 2 diabetes mellitus, ${ }^{30}$ which may suggest a role for DPPIV in the development of diabetic kidney disease. However, DPPIV activities in the plasma and all other target organs of diabetic mice were markedly reduced by DA-1229 treatment, with reductions of $70-80 \%$ in the plasma and kidneys. These results imply that the administered DA-1229 was successfully delivered to all organs and that it also systematically controlled DPPIV activity in diabetic mice. As expected, 

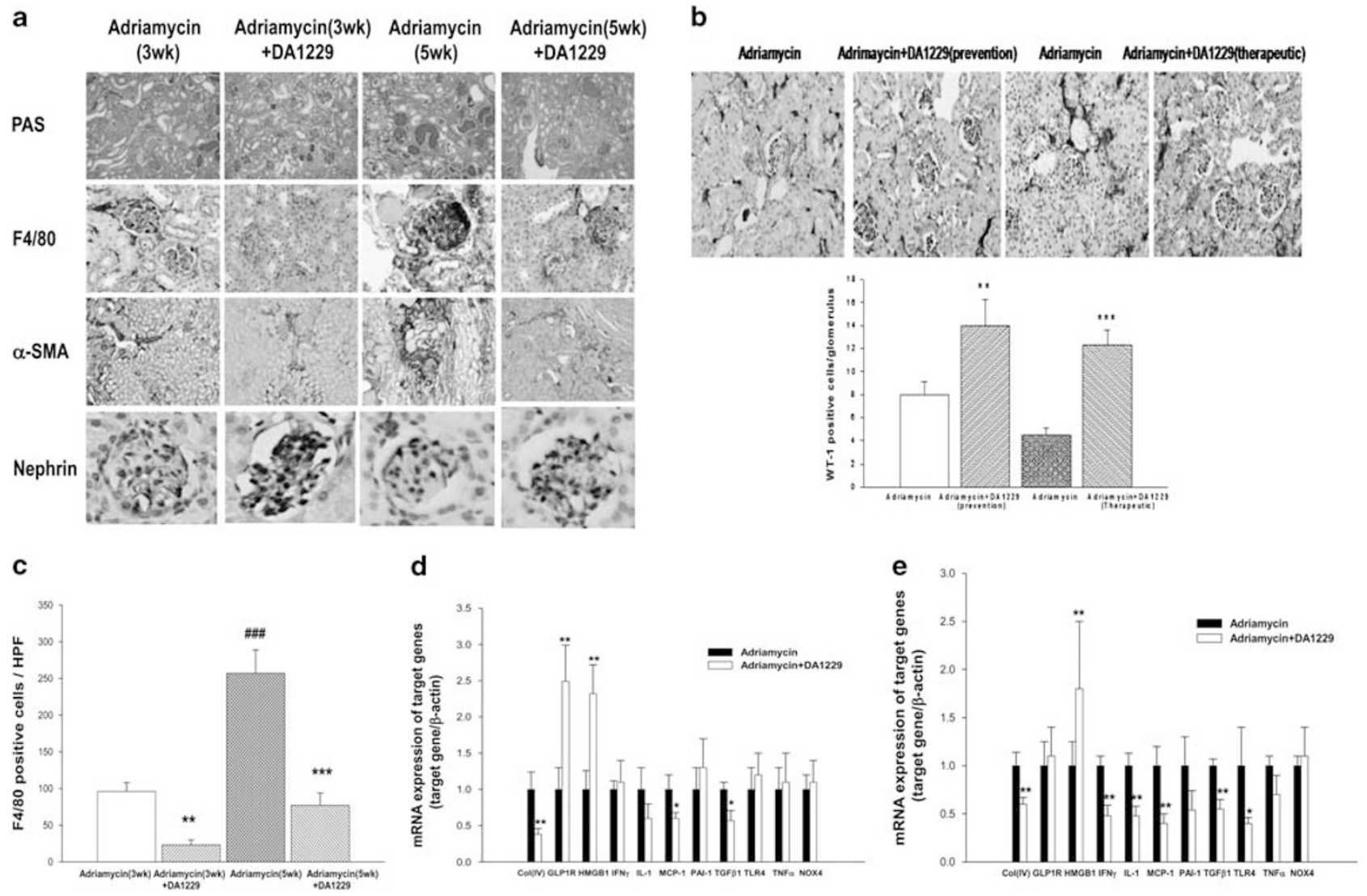

Figure 8 Effects of DA-1229 on renal structural changes in the adriamycin-induced nephrotoxicity model. (a) Effects of DA-1229 on renal histological changes. (b) Representative immunostaining for WT-1 and immunostaining score $\left({ }^{*} P<0.01,{ }^{* * *} P<0.001\right.$ vs adriamycin group). (c) Effects of DA-1229 on macrophage infiltration. (d, e) mRNA expression in renal cortical tissue in adriamycin-induced nephrotoxicity. Values are expressed as means \pm s.e.m. Original magnification $\mathrm{x} 400$ (PAS, F4/80, $a$-SMA, WT-1), x1000 (nephrin). ${ }^{*} P<0.05,{ }^{* *} P<0.01,{ }^{* *} P<0.001$ vs adriamycin group; ${ }^{\# \# \#} P<0.001$ vs adriamycin group at 3 weeks.

the plasma levels of active GLP-1 were significantly increased after DA-1229 treatment. However, these levels were not significantly different between diabetic $d b / d b$ mice and nondiabetic $d b / m$ mice.

In this study, we observed that DA-1229 improved dyslipidemia without affecting the serum fasting blood glucose level or the amount of food intake. Although no differences were observed regarding the proportions of fat and liver weight, these findings are in agreement with a previous study showing that the liver expression of DPPIV correlates with the histopathologic grades of nonalcoholic steatohepatitis and hepatosteatosis. ${ }^{31}$

The most important finding in this study is that DA-1229 mitigates the urinary excretion of albumin and mesangial expansion in renal tissue. Moreover, these effects are accompanied by the suppression of profibrotic and proinflammatory molecule synthesis. In support of the role of DPPIV inhibition in the inflammatory process, Nistala et $a l^{32}$ recently reported that DPPIV inhibition prevents glomerular and tubular injury through reduction in renal oxidative stress and inflammation in high-fat diet-induced mice independent of blood pressure and insulin sensitivity. Interestingly, we also found that DA-1229 improved renal lipid metabolism in the diabetic kidney. DA-1229 treatment markedly suppressed the expression of genes involved in cholesterol synthesis, such as HMG-CoA reductase. On the other hand, ABCA1, which modulates cholesterol efflux, was significantly upregulated by DA-1229 treatment.

Furthermore, here we observed for the first time that podocyte DPPIV activity increases in response to stimulation with high glucose and angiotensin II. In addition, nephrin expression was markedly downregulated in the glomeruli of $d b / d b$ mice compared with control $d b / m$ mice. Interestingly, DA-1229 treatment also increased nephrin expression in the glomeruli of diabetic mice. We also observed that numbers of WT-1-positive-stained cells in the glomeruli were significantly increased in DA-1229 treatment group compared with that in $d b / d b$ mice group. In addition, we observed that DA-1229 pretreatment significantly increased podocyte survival from high glucose-induced cytotoxic injury using MTT assay. These findings are in agreement with a recent study showing that the DPPIV inhibition prevents podocyte loss associated 
a

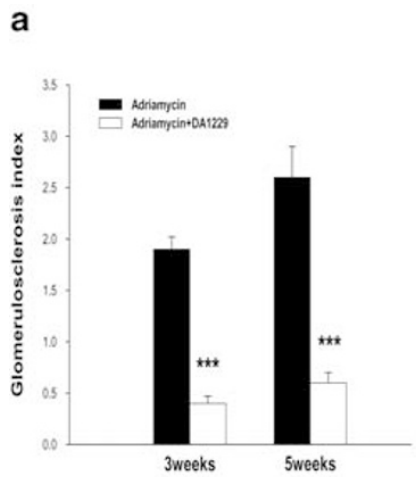

e

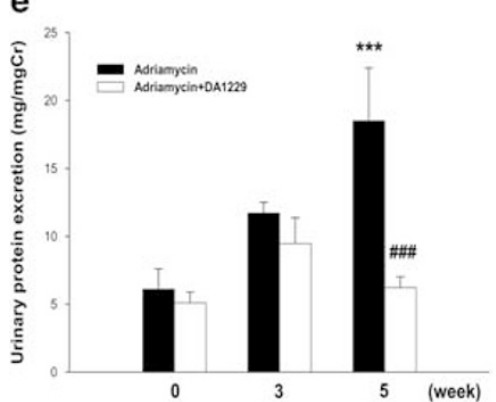

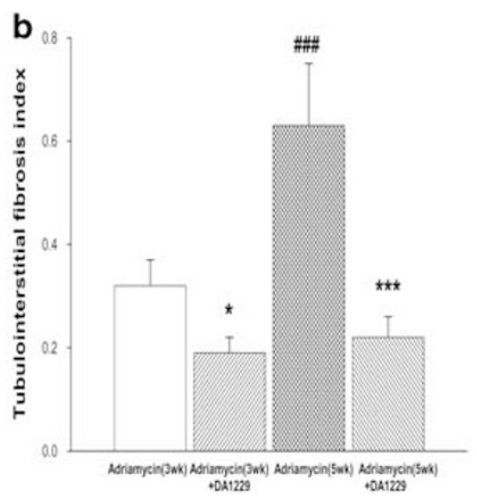

c

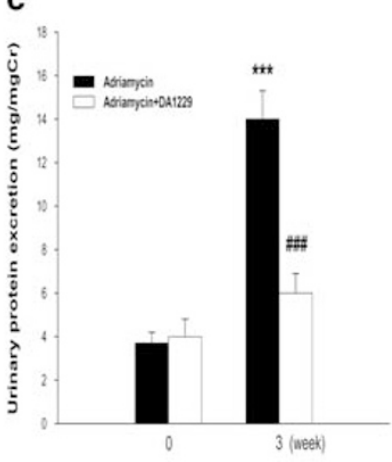

d

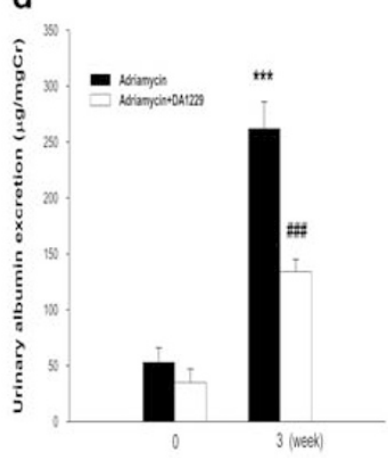

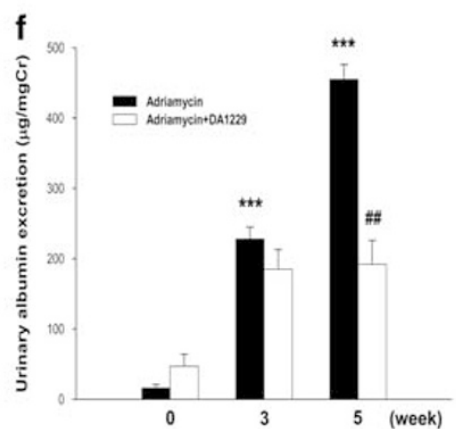

g

Adriamycin Adriamycin Adriamycin Adriamycin +DA1229 +DA1229

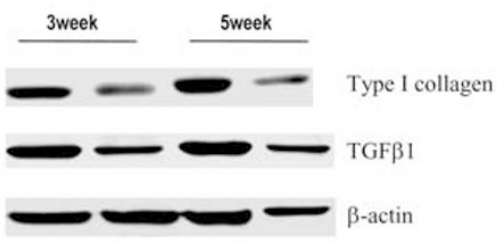

Figure 9 Effects of DA-1229 on urinary protein and albumin excretion in the adriamycin-induced nephrotoxicity model. (a, b) Effects of DA-1229 on

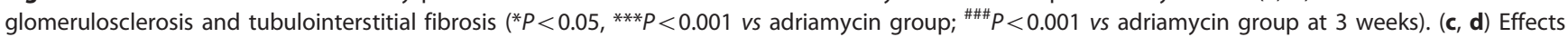
of DA-1229 on proteinuria and albuminuria in the preventive model of adriamycin-induced nephrotoxicity. (e, f) Effects of DA-1229 on proteinuria and albuminuria in the therapeutic model of adriamycin-induced nephrotoxicity. (g) Representative western blot showing the effects of DA-1229 on type I collagen and TGF- $\beta 1$ expression in renal cortical tissue. TGF- $\beta 1$, transforming growth factor 1 . For $\mathbf{c}-\mathbf{f}$, Student's $t$-test and the paired $t$-test were performed to compare two different groups at the same time point and responses within a single group at different time points, respectively. Values are expressed as means \pm s.e.m. Statistical analysis was performed between groups at the same time points. ${ }^{* *} P<0.001$ vs adriamycin (ADX) group at 0 week; ${ }^{\# \#} P<0.01,{ }^{\# \# \#} P<0.001$ vs adriamycin (ADX) group.

with the suppression of oxidative damage. ${ }^{33}$ Taken together, these results suggest that activated DPPIV may induce podocyte dysfunction, such as podocyte loss, which is accompanied by increased albuminuria. Another interesting finding was that various DPPIV inhibitors could differentially affect DPPIV activity and nephrin restoration. We found that DA-1229 and saxagliptin were the most potent inhibitors of DPPIV activity in podocytes, with DA-1229 showing the most potent effect on nephrin preservation in podocytes.

Recent studies have used animal models to investigate the possible beneficial effects of the DPPIV inhibitors sitagliptin, vildagliptin and linagliptin in diabetic nephropathy. ${ }^{13,14,34}$ These studies found that DPPIV inhibition led to reduced albuminuria and histological damage; these effects were associated with anti-inflammatory and antioxidant properties. However, it is difficult to determine whether the renal effects of DPPIV inhibitors are independent of their glucose-lowering effects. Therefore, in this study, we investigated the effects of DPPIV inhibition in adriamycin nephropathy model to rule out any indirect effects from blood sugar changes. ${ }^{35}$

Adriamycin-induced nephropathy is characterized by podocyte injury followed by glomerulosclerosis, tubulointerstitial inflammation and fibrosis. ${ }^{36}$ Interestingly, DPPIV activity in the kidney was significantly increased in adriamycin mice compared with control mice, whereas no significant differences were observed between the two groups regarding the plasma level of active GLP-1. Surprisingly, we found that DA-1229 significantly reduced albuminuria and proteinuria; improved the expression of inflammatory and fibrosis-related molecules, and decreased macrophage infiltration. To further support the role of DPPIV activity in macrophage infiltration, we also demonstrated that high glucose and angiotensin II stimulation markedly increased MCP-1 gene expression and MCP-1 protein secretion as well as increased DPPIV activity, and there was a significant positive correlation between DPPIV activity and supernatant MCP-1 levels in cultured podocytes. Moreover, DA-1229 treatment significantly prevented the urinary loss of nephrin in adriamycin mice and in $d b / d b$ mice. Nephrin is a crucial protein for maintaining the integrity of the slit diaphragm and nephrin excretion has been proposed to be an early indicator of podocyte injury, even before the onset of albuminuria. ${ }^{36,37}$ Collectively, these findings suggest that the renoprotective effects of DA-1229 are due to the suppression of DPPIV activity independent of the glucose-lowering effect and mediated by the prevention of podocyte injury. 
Our study differs from previous work, in that we directly determined DPPIV activity in the kidney, rather than simply measuring DPPIV expression. We showed that DPPIV activity was increased in the kidneys of diabetic mice and adriamycin nephropathy mice, and that DA-1229 treatment suppressed DPPIV activity, and that DA-1229 treatment resulted in improved renal function via podocyte protection.

In conclusion, our data suggest that DPPIV inhibitors may prevent renal disease progression in diabetic and nondiabetic kidney disease. These findings suggest that DA-1229 treatment is a promising novel strategy for targeting diabetic nephropathy, in addition to various other glomerular diseases affecting podocytes.

Supplementary Information accompanies the paper on the Laboratory Investigation website (http://www.laboratoryinvestigation.org)

\section{ACKNOWLEDGMENTS}

We thank the Dong-A ST Research Institute, Yongin-si, Gyeonggi-do, Republic of Korea for kindly providing DA-1229. This work was supported by a special grant from Korea University (Q1303991).

\section{DISCLOSURE/CONFLICT OF INTEREST}

The authors declare no conflict of interest.

1. Martin JH, Deacon CF, Gorrell MD et al. Incretin-based therapiesreview of the physiology, pharmacology and emerging clinical experience. Intern Med J 2011;41:299-307.

2. Campos RV, Lee YC, Drucker DJ. Divergent tissue-specific and developmental expression of receptors for glucagon and glucagonlike peptide-1 in the mouse. Endocrinology 1994;134:2156-2164.

3. Bullock BP, Heller RS, Habener JF. Tissue distribution of messenger ribonucleic acid encoding the rat glucagon-like peptide-1 receptor. Endocrinology 1996;137:2968-2978.

4. Hirata K, Kume S, Araki S et al. Exendin-4 has an anti-hypertensive effect in salt-sensitive mice model. Biochem Biophys Res Commun 2009;380:44-49.

5. Sivertsen J, Rosenmeier J, Holst JJ et al. The effect of glucagon-like peptide 1 on cardiovascular risk. Nat Rev Cardiol 2012;9:209-222.

6. Drucker DJ. Incretin action in the pancreas: potential promise, possible perils, and pathological pitfalls. Diabetes 2013;62:3316-3323.

7. Sharkovska Y, Reichetzeder C, Alter M et al. Blood pressure and glucose independent renoprotective effects of dipeptidyl peptidase-4 inhibition in a mouse model of type-2 diabetic nephropathy. J Hypertens 2014;32:2211-2223.

8. Mori H, Okada Y, Arao T et al. Sitagliptin improves albuminuria in patients with type 2 diabetes mellitus. J Diabetes Investig 2014;5:313-319.

9. Marques C, Mega C, Gonçalves A et al. Sitagliptin prevents inflammation and apoptotic cell death in the kidney of type 2 diabetic animals. Mediators Inflamm 20142014; 538737.

10. Nakashima S, Matsui T, Takeuchi $M$ et al. Linagliptin blocks renal damage in type 1 diabetic rats by suppressing advanced glycation end products-receptor axis. Horm Metab Res 2014;46:717-721.

11. Kanasaki K, Shi S, Kanasaki M et al. Linagliptin-mediated DPP-4 inhibition ameliorates kidney fibrosis in streptozotocin-induced diabetic mice by inhibiting endothelial-to-mesenchymal transition in a therapeutic regimen. Diabetes 2014;63:2120-2031.

12. Kodera R, Shikata K, Takatsuka T et al. Dipeptidyl peptidase-4 inhibitor ameliorates early renal injury through its anti-inflammatory action in a rat model of type 1 diabetes. Biochem Biophys Res Commun 2014;443: 828-833.

13. Mega $\mathrm{C}$, de Lemos ET, Vala $\mathrm{H}$ et al. Diabetic nephropathy amelioration by a low-dose sitagliptin in an animal model of type 2 diabetes (Zucker diabetic fatty rat). Exp Diabetes Res 20112011; 162092.
14. Liu WJ, Xie SH, Liu YN et al. Dipeptidyl peptidase IV inhibitor attenuates kidney injury in streptozotocin-induced diabetic rats. J Pharmacol Exp Ther 2012;340:248-255.

15. Pagtalunan ME, Miller $\mathrm{PL}$, Jumping-Eagle $\mathrm{S}$ et al. Podocyte loss and progressive glomerular injury in type ii diabetes. J Clin Invest 1997;99: 342-348.

16. Wolf G, Chen S, Ziyadeh FN. From the periphery of the glomerular capillary wall toward the center of disease: podocyte injury comes of age in diabetic nephropathy. Diabetes 2005;54:1626-1634.

17. Patrakka J, Kestila M, Wartiovaara J et al. Congenital nephrotic syndrome (NPHS1): features resulting from different mutations in Finnish patients. Kidney Int 2000;58:972-980.

18. Koziell A, Grech V, Hussain S et al. Genotype/phenotype correlations of NPHS1 and NPHS2 mutations in nephrotic syndrome advocate a functional inter-relationship in glomerular filtration. Hum Mol Genet 2002;11:379-388.

19. Doublier S, Ruotsalainen V, Salvidio G et al. Nephrin redistribution on podocytes is a potential mechanism for proteinuria in patients with primary acquired nephrotic syndrome. Am J Pathol 2001;158:1723-1731.

20. Nistala R, Habibi J, Aroor A et al. DPP4 inhibition attenuates filtration barrier injury and oxidant stress in the zucker obese rat. Obesity (Silver Spring) 2014;22:2172-2179.

21. Tinoco AD, Tagore DM, Saghatelian A. Expanding the dipeptidyl peptidase 4-regulated peptidome via an optimized peptidomics platform. J Am Chem Soc 2010;132:3819-3830.

22. Kim HW, Lee JE, Cha JJ et al. Fibroblast growth factor 21 improves insulin resistance and ameliorates renal injury in $\mathrm{db} / \mathrm{db}$ mice. Endocrinology 2013;154:3366-3376.

23. Ma LJ, Nakamura S, Aldigier JC et al. Regression of glomerulosclerosis with high-dose angiotensin inhibition is linked to decreased plasminogen activator inhibitor-1. J Am Soc Nephrol 2005;16:966-976.

24. Bonegio RG, Fuhro R, Wang Z et al. Rapamycin ameliorates proteinuria associated tubulointerstitial fibrosis inflammation and fibrosis in experimental membranous nephropathy. J Am Soc Nephrol 2005;16: 2063-2072.

25. Kim HJ, Kwak WY, Min JP et al. Discovery of DA-1229: a potent, long acting dipeptidyl peptidase-4 inhibitor for the treatment of type 2 diabetes. Bioorg Med Chem Lett 2011;21:3809-3812.

26. Cho JM, Jang $\mathrm{HW}$, Cheon $\mathrm{H}$ et al. A novel dipeptidyl peptidase IV inhibitor DA-1229 ameliorates streptozotocin-induced diabetes by increasing $\beta$-cell replication and neogenesis. Diabetes Res Clin Pract 2011;91:72-79.

27. Kim MK, Chae YN, Kim HD et al. DA-1229, a novel and potent DPP4 inhibitor, improves insulin resistance and delays the onset of diabetes. Life Sci 2012;90:21-29.

28. Kim TE, Lim KS, Park MK et al. Evaluation of the pharmacokinetics, food effect, pharmacodynamics, and tolerability of DA-1229, a dipeptidyl peptidase IV inhibitor, in healthy volunteers: first-in-human study. Clin Ther 2012;34:1986-1998.

29. Stefanovic V, Ardaillou N, Vlahovic P et al. Interferon-gamma induces dipeptidylpeptidase iv expression in human glomerular epithelial cells. Immunology 1993;80:465-470.

30. Yang J, Campitelli J, Hu G et al. Increase in dpp-iv in the intestine, liver and kidney of the rat treated with high fat diet and streptozotocin. Life Sci 2007;81:272-279.

31. Balaban YH, Korkusuz P, Simsek $\mathrm{H}$ et al. Dipeptidyl peptidase IV (DDP IV) in NASH patients. Ann Hepatol 2007;6:242-250.

32. Nistala R, Habibi J, Lastra G et al. Prevention of obesity-induced renal injury in male mice by DPP4 inhibition. Endocrinology 2014;155: 2266-2276.

33. Jung ES, Kim JH, Kim SH et al. Gemigliptin improves renal function and attenuates podocyte injury in mice with diabetic nephropathy. Eur J Pharmacol 2015;761:116-124.

34. Alter ML, Ott IM, von Websky $\mathrm{K}$ et al. Dpp-4 inhibition on top of angiotensin receptor blockade offers a new therapeutic approach for diabetic nephropathy. Kidney Blood Press Res 2012;36:119-130.

35. Lee VW, Harris DC. Adriamycin nephropathy: a model of focal segmental glomerulosclerosis. Nephrology (Carlton) 2011;16:30-38.

36. Wolf G, Ziyadeh FN. Molecular mechanisms of diabetic renal hypertrophy. Kidney Int 1999;56:393-405.

37. Wolf G, Ziyadeh FN. Cellular and molecular mechanisms of proteinuria in diabetic nephropathy. Nephron Physiol 2007;106:26-31. 